\title{
Analysis and Modeling of Friction Stir Processing-Based Crack Repairing in 2024 Aluminum Alloy
}

\author{
Jun-Gang Ren $^{1} \cdot$ Lei Wang ${ }^{2} \cdot$ Dao-Kui Xu ${ }^{3} \cdot$ Li-Yang Xie ${ }^{1} \cdot$ Zhan-Chang Zhang $^{2}$
}

Received: 13 July 2016/Revised: 24 August 2016/Published online: 23 September 2016

(C) The Chinese Society for Metals and Springer-Verlag Berlin Heidelberg 2016

\begin{abstract}
A friction stir processing-based method was used to repair cracks in the 2024 aluminum alloy plates. The temperature field and plastic material flow pattern were analyzed on the basis of experimental and finite element simulation results. Microstructure and tensile properties of the repaired specimens were studied. The results showed that the entire crack repairing was a solid-phase process and plastic materials tended to flow toward the shoulder center and then resulted in the repairing of cracks. Meanwhile, the coarse grain structures were refined in repaired zone (RZ), while the grains in thermal-mechanically affected zone and heat-affected zone were elongated and driven to grow up. Meanwhile, large phases are crushed into small particles and dispersed inside the RZ. Finally, the strength of the repaired specimens can be restored dramatically and their ductility can be partially restored. After heat treatment, the tensile properties of the repaired specimens can be further enhanced.
\end{abstract}

KEY WORDS: Friction stir processing; Crack repairing; Aluminum alloy; Microstructure; Hardness; Tensile properties

\section{Introduction}

Service reliability of mechanical products is an urgent problem to be solved for their engineering applications [1]. The most dangerous damage that affects service lives of materials and structural components is the cracking occurrence. Generally, the cracking failure has some

Available online at http://link.springer.com/journal/40195

Lei Wang

leiwang@sau.edu.cn

1 Department of Mechanical Engineering and Automation, Northeastern University, Shenyang 110004, China

2 Department of Electromechanical Engineering, Shenyang Aerospace University, Shenyang 110136, China

3 Key Laboratory of Nuclear Materials and Safety Assessment, Institute of Metal Research, Chinese Academy of Sciences, Shenyang 110016, China intrinsic features such as multiplicity, suddenness and repeatability.

Due to external shocks or corrosive environment, many cracks or crack-like damages will appear on the surfaces of the structural components. Moreover, pores and microcracks can be introduced in the interior of materials during the manufacturing processes such as welding, hot treating and forging. Then, these defects will gradually develop to macro-cracks and lead to the early failure of the structures. According to the statistics, more than 50\% fracture accidents can be attributed to fatigue cracking [2]. With the extension of service time, the cracking probability will increase for the engineering structures. Supposing that cracks could be repaired before final fracture, some catastrophic accidents would be avoided and the service lives of the structures could be prolonged. Unfortunately, so far, the controlling and repairing of the cracks are far from expectation.

Nowadays, studies about crack repairing and healing mainly focused on non-metallic brittle materials such as 
ceramic, concrete, glass and polymers [3-8]. Moreover, self-healing for some underaged aluminum alloys and austenitic stainless steels could also be achieved when their damages were limited to a microscopic scale under certain service conditions [9-11]. However, when the macroscopic cracks are formed, it will be difficult for metals to be selfhealed unless some type of external energy was introduced such as heat, electricity, sonic wave, luminous flux or mechanical energy.

Although several crack repairing methods have been proposed, most of repairing results are still undesirable. Hosoi et al. [12] reported that the crack could be closed by applying a high-density current at the crack tip, but the crack growth rate decreased just after the application of current and then restored to the comparable value of the unrepaired specimen under the constant loads. Murray and Clare [13] utilized electro-beam irradiation to repair surface cracks introduced by electrical-discharge machining, but the formed pits were sensitive to corrosive environment. Zheng et al. [14] proposed an electrochemical crack repairing method, but some pores were found at the healing interface after the crack repairing process. As for the other crack repairing methods such as laser cladding, welding, bonding and reinforcing, they still have some disadvantages including high cost, poor repairing quality and recurrence of cracks.

Friction stir welding (FSW) is an adaptive technique for the connection of aluminum alloys, and fine equiaxed grain structure can be obtained due to dynamic recrystallization in the weld nugget [15]. As a result, a technique named friction stir processing (FSP) was developed to produce fine and super-fine grains [16, 17]. In this work, the friction stir technique was utilized to repair surface cracks in aluminum alloy plates, as illustrated in Fig. 1, and a specially designed repairing tool was rotated and moved along the crack path with the tool shoulder end contacting with the specimen surface. Materials nearby the crack were flowed and transferred across the crack. As a result, the crack gap was fulfilled by the flowed materials and fine equiaxed grains were formed due to the dynamic recrystallization.

So far, FSW and FSP have been used as the joining techniques for engineering materials and structures to

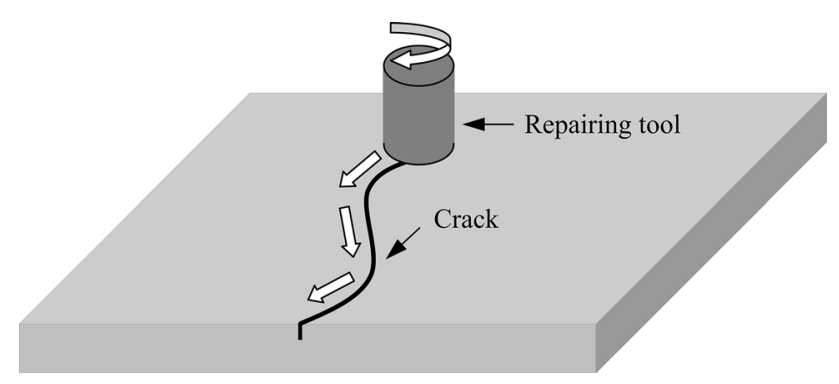

Fig. 1 Outline of friction stir processing for repairing crack obtain fine or super-fine grain structures ensuring the high quality of welds [15-17], but there have been a few studies to be reported on the FSW technique applying into crack repairing field. This study is focused on the friction stir processing repairing crack of 2024 aluminum alloy, and the emphasis is placed on the effect of different repairing parameters on microstructure, temperature and thermoplastic evolution, mechanical properties of the repaired specimens.

\section{Experimental Procedures}

\subsection{Material and Specimen Preparation}

The material used for crack repairing is 2024-T4, a heattreatable high-strength aluminum alloy that is widely used in skins, airframes, ribbed beams and bulkheads of aircrafts. The chemical composition of the T2024-T4 alloy is given in Table 1. The basic physical and mechanical properties of the material are listed in Table 2.

The 2024-T4 plate with a thickness of $4 \mathrm{~mm}$ was fabricated into $1000 \mathrm{~mm} \times 240 \mathrm{~mm} \times 4 \mathrm{~mm}$ specimens, and then, a pre-crack was introduced by using electrical-discharge cutting machine along the center line of the long side. The depth of pre-crack was $1 \mathrm{~mm}$. Before repairing, all the specimens were cleaned by acetone and deionized water.

\subsection{Crack Repairing Process}

The crack repairing process was carried out on an FSW3LM-4012 friction stir welding machine, as shown in Fig. 2. The pre-cracked specimens were rigidly clamped on the worktable, and a specially designed repairing tool made from tool steel with a cylindrical shoulder was rotated and moved along the crack path. The diameter of the shoulder was $10 \mathrm{~mm}$ with ringed grooves, and a $2^{\circ}$ tilt angle of the repairing tool was used to strengthen the forging action of the shoulder. To record the temperature data during the repairing process, four thermocouples were plugged inside the plate with distances of $1,5,9$ and $13 \mathrm{~mm}$ from the shoulder edge, respectively.

\subsection{Modeling of Temperature Distribution and Material Flow Pattern}

The commercial FEM software ABAQUS was utilized to simulate the temperature distribution of the crack repairing process. Then, the calculated results were verified by the data measured from thermocouples. Afterward, a thermalfluid simulation was implemented in FLUENT for calculating the material flow. The viscosity of the material was 
Table 1 Chemical compositions of aluminum alloy 2024-T4 (wt\%)

\begin{tabular}{lllllllll}
\hline $\mathrm{Si}$ & $\mathrm{Fe}$ & $\mathrm{Cu}$ & $\mathrm{Mg}$ & $\mathrm{Zn}$ & $\mathrm{Ti}$ & $\mathrm{Mn}$ & $\mathrm{Other}$ & $\mathrm{Al}$ \\
\hline 0.5 & 0.5 & $3.8-4.9$ & $1.2-1.8$ & 0.3 & 0.15 & $0.3-0.9$ & $\mathrm{Ni}: 0.1, \mathrm{Fe}+\mathrm{Ni}: 0.5$ & $\mathrm{Bal}$. \\
\hline
\end{tabular}

Table 2 Physical and mechanical properties of aluminum alloy 2024-T4

\begin{tabular}{lllll}
\hline Melting range $\left({ }^{\circ} \mathrm{C}\right)$ & Hardness $(\mathrm{HV})$ & $\sigma_{\mathrm{b}}(\mathrm{MPa})$ & $\sigma_{\mathrm{s}}(\mathrm{MPa})$ & $\delta(\%)$ \\
\hline $502-638$ & 126 & 467 & 328 & 19.5 \\
\hline
\end{tabular}

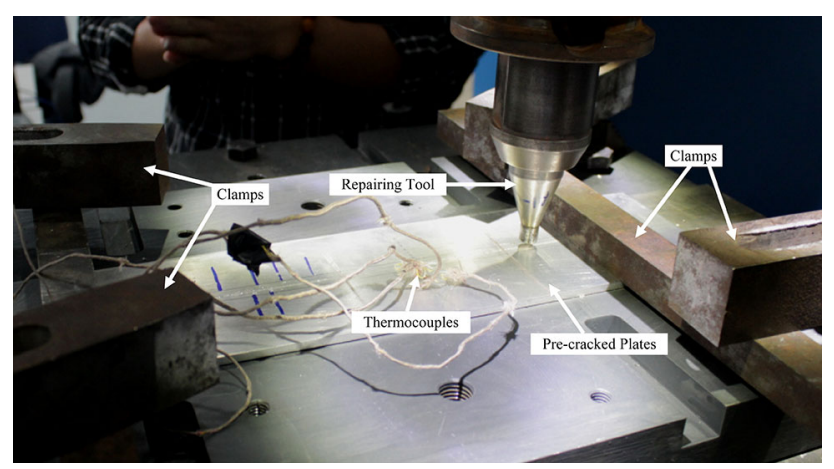

Fig. 2 Crack repairing process

regarded to change with temperature and strain rate according to Eq. (1):

$\eta=\frac{\sigma(T, \bar{\varepsilon})}{3 \bar{\varepsilon}}$

where $\bar{\varepsilon}$ is strain rate, $T$ is temperature, $\sigma$ is flow stress and can be calculated by Zener-Hollomon equation as follows:

$\sigma(T, \bar{\varepsilon})=\frac{1}{\alpha} \ln \left\{\left(\frac{Z(T, \bar{\varepsilon})}{A}\right)^{\frac{-1}{n}}+\left[1+\left(\frac{Z(T, \bar{\varepsilon})}{A}\right)^{\frac{2}{n}}\right]^{\frac{1}{2}}\right\}$.

$Z(T, \bar{\varepsilon})=\bar{\varepsilon} \exp \left(\frac{Q}{R T}\right)$,

where $Q$ is activation energy, $R$ is universal gas constant, and $\alpha, A, n$ are the constants related to materials.

According to Ref. [18], the parameters used in this paper for calculating the viscosity are as follows: $Q=$ $176,876 \mathrm{~J} \mathrm{~mol}^{-1}, R=8.314 \mathrm{~J} \mathrm{~mol}^{-1} \mathrm{~K}^{-1}, \alpha=0.0118 \mathrm{MPa}^{-1}$, $\ln A=31.43 \mathrm{~s}^{-1}, n=5.86$.

\subsection{Microstructure and Mechanical Property Tests}

After crack repairing, the specimens were cross-sectioned using an electrical-discharge cutting machine to make metallographic samples, and then polished and etched with Keller's reagent $(2 \mathrm{ml}$ hydrofluoric acid, $3 \mathrm{ml}$ hydrochloric acid, $5 \mathrm{ml}$ nitric acid and $190 \mathrm{ml}$ water) for optical observation on an Olympus GX51 microscope.

Vickers hardness distributions were measured along the cross section as per standard ISO 6507-1-2005 using an HVS-1000A micro-hardness tester with distances between neighboring points of $0.25 \mathrm{~mm}$ near the thermal-mechanically affected zone (TMAZ), $1 \mathrm{~mm}$ in the central repaired zone and $0.5 \mathrm{~mm}$ in other zones under the load of $5 \mathrm{~N}$ for $12 \mathrm{~s}$. Four section lines from the top to bottom of the repaired specimen were selected with distances of $0.5,1,2$ and $3 \mathrm{~mm}$ from the repaired top surface, respectively.

Tensile tests were carried out as per standard ISO 4136-2001 with the tensile axis being perpendicular to the repaired zone to determine the repairing quality. The tensile specimen size is schematically shown in Fig. 3. Then, the tested specimens were examined to identify fracture sites and fracture surfaces by using scanning electron microscope.

\section{Results and Discussion}

\subsection{Temperature Distribution and Plastic Material Flow Pattern}

Figure 4 shows that the temperature cycle curves have similar development tendency at positions 1, 5, 9 and $13 \mathrm{~mm}$ away from the shoulder edge. Moreover, it can be seen that the temperature increases gradually at the initial stage and then reaches a peak value when the shoulder passes the sections where the thermocouples were

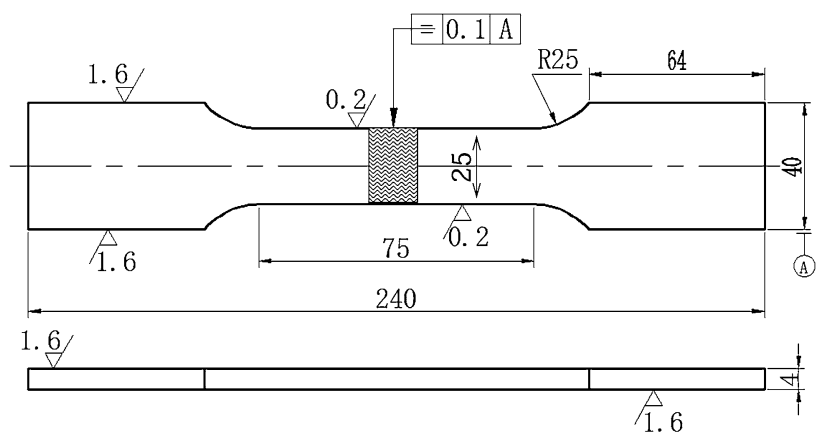

Fig. 3 Dimension of the tensile specimen 


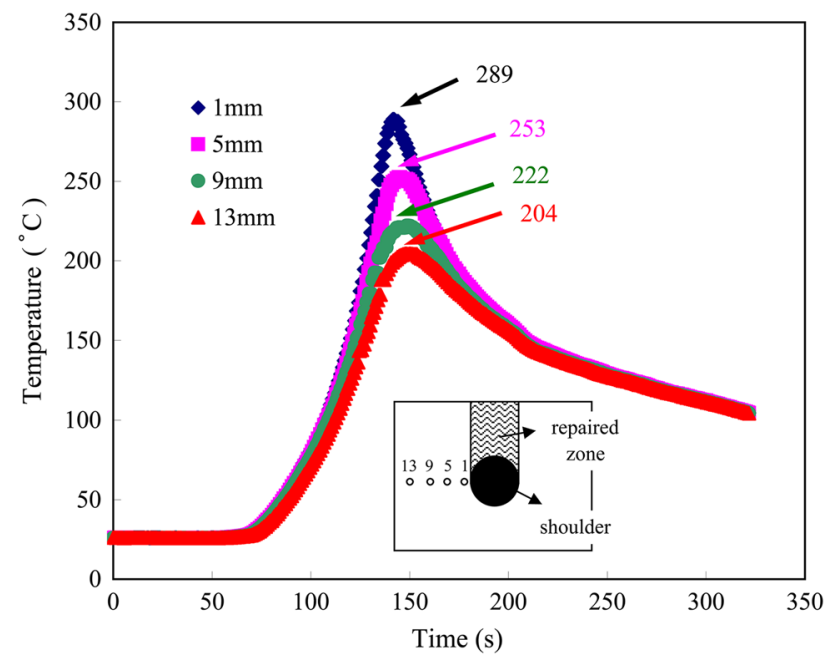

Fig. 4 Temperature cycle curves from thermocouples $(\omega=$ $1100 \mathrm{rpm}, v=50 \mathrm{~mm} / \mathrm{min}$ )

arranged. With the advancing of the shoulder, temperature starts to decrease gradually from the peak value. Moreover, the peak temperature varies with the distances from the shoulder edge of thermocouples. The determined peak temperatures at four selected positions of 1, 5, 9 and $13 \mathrm{~mm}$ away from the shoulder edge are 289, 253, 222 and $204{ }^{\circ} \mathrm{C}$, respectively. Compared with the melting range of 2024 alloy, these temperatures are much lower (see Table 2).

Regrettably, the thermocouple cannot be put inside the stirring zone due to the acute plastic deformation of the material. As a result, it is difficult to obtain the temperature distribution beneath the shoulder. Then, the FEM method was utilized to simulate the thermal cycle of the repairing process.

Figure 5 shows the temperature distribution calculated from FEM simulation. It reveals that the temperatures of the specimen sections vary along the width and depth directions (Fig. 5a). Three typical nodes at locations of 0,2 and $4 \mathrm{~mm}$ from the specimen top are selected to study the temperature cycles in the stirring zone. It can be seen in Fig. 5b the tendency of the temperature cycle curves at three nodes is quite similar except for their peak values, which reach the highest values of $381{ }^{\circ} \mathrm{C}$ at point $1,349{ }^{\circ} \mathrm{C}$ at point 2 and $341{ }^{\circ} \mathrm{C}$ at point 3 .

In FSW, frictional heat can be produced by both the rotating shoulder and pin [19]. However, due to the absence of pin in FSP-based crack repairing, materials are mainly softened by the frictional heat from the rotating shoulder. Based on the temperature measurement and relevant simulation, it demonstrates that all the temperatures during crack repairing are much lower than the melting point of 2024 alloy (Table 2), indicating that the entire crack repairing is a solid-phase process. Moreover, it means that a smaller specimen distortion, a lower residual stress level and less effect could be induced on the base material compared with the fusion methods.

Figure 6 shows the asymmetric flow pattern of the plastic material during the crack repairing process by FLUENT simulation. From the top view, it can be divided into advancing side (AS) and retreating side (RS) on the basis of the directions between the tool advancing velocity and the circumferential speed of the shoulder. Then, it can
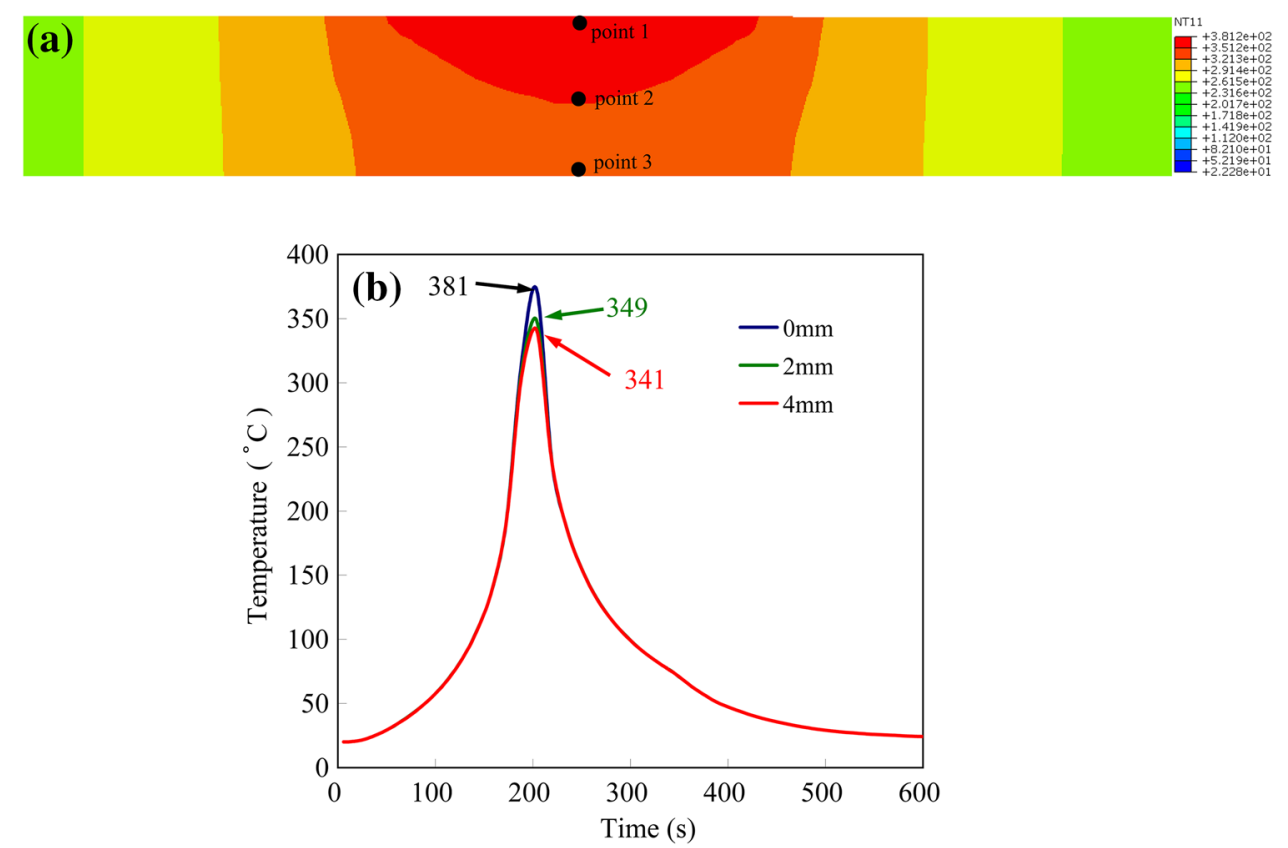

Fig. 5 a Temperature distributions from the FEM simulation, $\mathbf{b}$ temperature cycle curves at point $1,2,3$ in $\mathbf{a}(\omega=1100 \mathrm{rpm}, v=50 \mathrm{~mm} / \mathrm{min})$ 

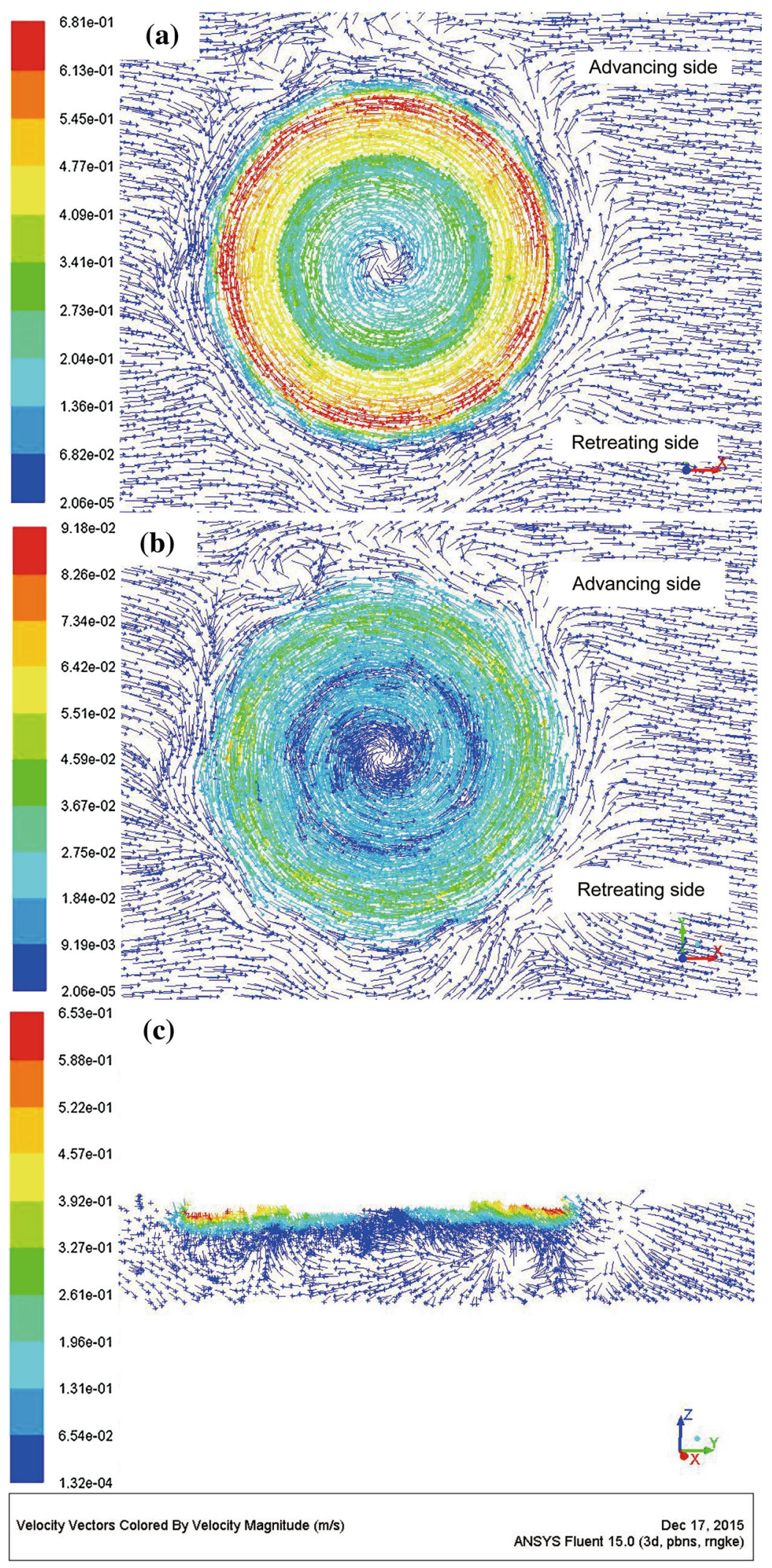

Fig. 6 Plastic material flow patterns: a specimen top, b $1 \mathrm{~mm}$ underneath the specimen top, c the longitudinal section $(\omega=1100 \mathrm{rpm}$, $v=50 \mathrm{~mm} / \mathrm{min}$ ) 
easily result in the anisotropic response of the microstructures and mechanical properties [20]. It can be seen that in the AS region, tool advancing velocity and the circumferential speed of the shoulder are same. Moreover, flow pattern of plastic material near the shoulder is regularly along the advancing direction. However, in RS region (i.e., the directions of tool advancing velocity and the circumferential speed of the shoulder are opposite), the plastic material flow pattern is quite chaotic.

In addition, the materials beneath the shoulder have different flow velocities. Due to the higher circumferential speed, a higher velocity exists for the material far away from the shoulder center, as shown in Fig. 6a. For the materials with $1 \mathrm{~mm}$ underneath the top surface of the specimen, the rotating and stirring actions of the shoulder are much weaker, resulting in the decrease of flow velocities of the material. From Fig. $6 c$, it can be seen that most materials move downward due to the forging action of the shoulder [21], but there still exist a few portions of the materials having upward motion tendency resulted from the flow stress. Most importantly, the plastic materials tend to flow toward the shoulder center for filling the crack gap and then result in the repairing of cracks.

\subsection{Microstructures of the Repaired Specimen}

The macrograph of the 2024-T4 repaired specimen is shown in Fig. 7. It reveals that a shallow "bowl" shapelike repaired zone is formed due to the absence of the pin beneath the tool. The repaired specimen can be divided into four distinguished zones, i.e., repaired zone (RZ), thermalmechanically affected zone (TMAZ), heat-affected zone (HAZ) and the base material (BM), which are a little different from the friction stir weld, and especially the onion ring feature in the repaired zone cannot be observed. Generally, onion ring feature is the typical microstructure feature in FSW joints [22, 23]. Moreover, the microstructure in different zones changes gradually, as shown in Fig. 8.

The slightly elongated and large grain structures of 2024 BM (Fig. 8a) are refined in the RZ because of the stirring and forging action of the repairing tool. This process will produce heat input and large plastic strain rate of the

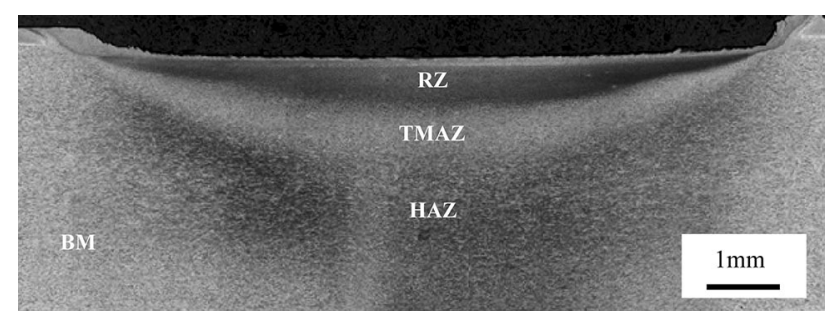

Fig. 7 Macrograph of the 2024-T4 repaired specimen materials underneath the shoulder and then result in entirely dynamic recrystallization with larger grains. Meanwhile, large phases are crushed into small particles and dispersed inside the RZ (Fig. 8d). Basically, the RZ mainly locates at the upper part of the repaired specimen (Fig. 7), which is not like the nugget zone (NZ) of friction stir weld being able to exist throughout the whole thickness of the specimen [23, 24],

The transition zone from RZ to TMAZ is denoted in Fig. 8c. It reveals that microstructures near the RZ present partially dynamically recrystallized grains, while grains near the HAZ are remarkably elongated. Due to the deeper position than that of the RZ, materials in the TMAZ experienced lower thermal cycle and insufficient strain rate, which cannot lead to entirely dynamic recrystallization [25]. As a result, most grains in the TMAZ are just elongated by the rotation of the repairing tool, and the grain size is considerably larger than that in the RZ. Nearby the TMAZ, materials in HAZ are just subjected to thermal cycle but no plastic deformation (Fig. 8b), grains and precipitates will grow to a larger size compared to those of the BM, exhibiting a typical overaging feature [26]. The average grain size in the HAZ is $45-55 \mu \mathrm{m}$, whereas the average grain size in the BM is $30-40 \mu \mathrm{m}$.

\subsection{Micro-hardness Profiles of the Repaired Specimens}

Figure 9 depicts the micro-hardness profiles of the repaired specimen, showing typical "W" shapes with the measured area moving from center of the repaired zone toward the TMAZ, HAZ and unaffected base material. It can be seen that due to the thermal cycle during the friction stir repairing process, the overaged microstructure could form, resulting in a drop in hardness of the repaired zone. For the precipitation strengthening aluminum alloys, the distribution of precipitated particles could remarkably influence the micro-hardness. The weakest point exhibits at the TMAZ/HAZ boundaries, materials of which experienced thermal cycle and mechanical shearing during the repairing process, leading to the dissolution of aging precipitates and formation of elongated grain structures. As for the material in RZ, its micro-hardness shows a partial recovery because of the uniformly distributed fine grains resulted from the dynamic recrystallization. The peak value of hardness in $\mathrm{RZ}$ can reach over $110 \mathrm{HV}$, which is similar to that of the 2024 FSW joint [27].

Meanwhile, micro-hardness profiles beneath the top surface show somewhat higher values at the TMAZ/HAZ boundaries than the top surface counterpart. With the increase in the distances from the top surface, the materials near TMAZs experienced lower thermal cycle, causing less precipitate dissolution. On the other hand, hardness 
recoveries in RZs become weaker with the increase in the distances from top surface. For the materials far away from the top surface in RZs, mechanical shearing stresses are not strong enough to cause totally dynamic recrystallization. Then, the recrystallized fine grain volume fraction is not comparable to the surface counterpart. As a result, the lowest hardness $(\sim 82 \mathrm{HV})$ of the repaired specimen locates at the TMAZ/HAZ boundaries on the surface, while the lowest hardness $(\sim 103 \mathrm{HV})$ of obtained data in RZs locates at the area with a way of $3 \mathrm{~mm}$ beneath the top surface.

\subsection{Tensile Properties of the Repaired Specimens}

The tensile properties of the specimens before and after repairing are listed in Table 3. Compared to the base material, tensile properties of the pre-cracked material are relatively low. More seriously, the ductility of pre-cracked specimens becomes negligible. After repairing, the tensile strength and yield strength of the repaired specimen can be

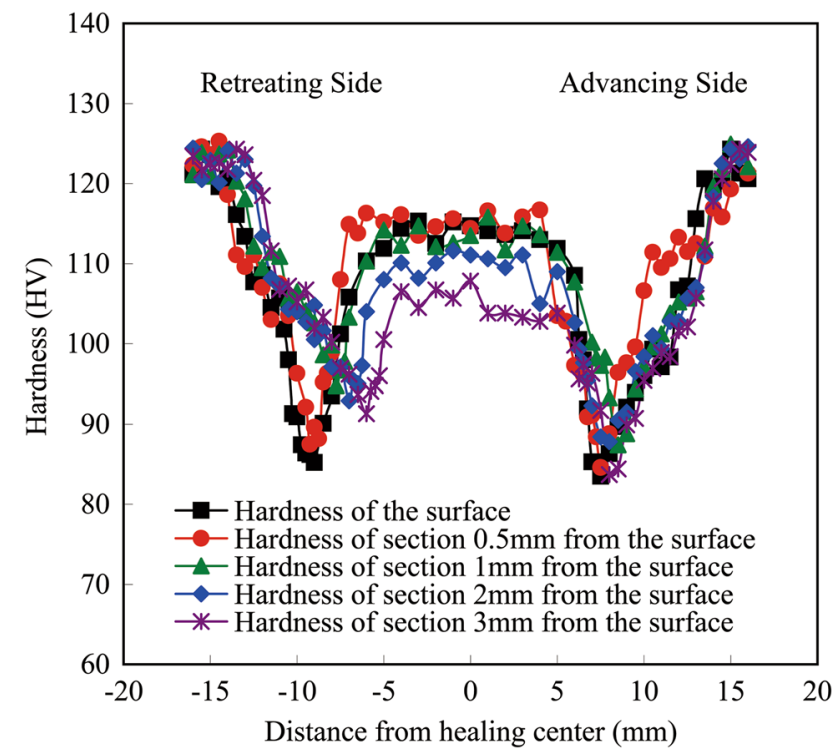

Fig. 9 Micro-hardness profiles of the repaired specimen across the section $(\omega=1100 \mathrm{rpm}, v=50 \mathrm{~mm} / \mathrm{min})$
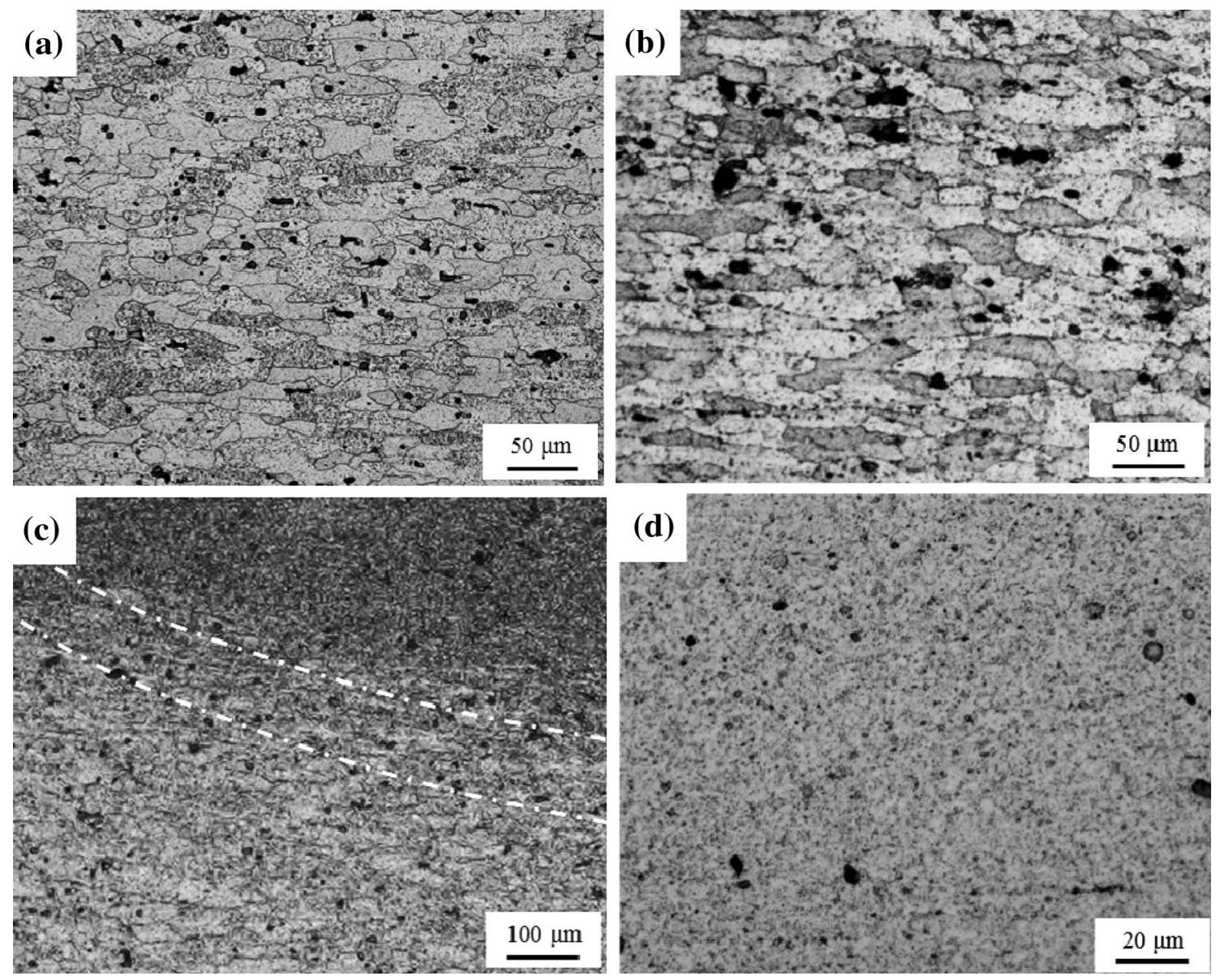

Fig. 8 Microstructures of a BM, b HAZ, c TMAZ, d RZ 
Table 3 Tensile properties of the specimens before and after repairing

\begin{tabular}{|c|c|c|c|c|}
\hline Specimen & $\sigma_{\mathrm{b}}(\mathrm{MPa})$ & $\sigma_{0.2}(\mathrm{MPa})$ & $\delta(\%)$ & $\varphi(\%)$ \\
\hline Base material & 465.8 & 307.5 & 19.5 & 24.6 \\
\hline Pre-cracked specimen & 204.3 & 121.3 & 0.8 & 2.9 \\
\hline Repaired specimen $^{\mathrm{a}}$ & 426.3 & 290.1 & 7.0 & 15.3 \\
\hline Repaired specimen after heat treatment ${ }^{\mathrm{a}}$ & 436.2 & 295.3 & 10.2 & 16.9 \\
\hline
\end{tabular}

${ }^{a}$ For repaired specimens, the repairing parameters were $\omega=700 \mathrm{rpm}$ and $v=110 \mathrm{~mm} / \mathrm{min}$

restored and reach about 91.5 and $94.3 \%$ those of the base material, respectively. Meanwhile, the ductility is partly restored. After heat treatment, the tensile properties of the repaired specimen can be further enhanced, resulting in the slight increase in tensile strength and yield strength, and both the elongation and reduction of area can exceed 52\% that of the base material counterpart.

Figures 10 and 11 show the effect of repairing parameters on the tensile properties of repaired specimens. If unsuitable repairing parameters were utilized, the tensile properties of pre-cracked specimens cannot be restored ideally. It can be seen from Fig. 10 that obviously high tensile properties can be obtained when the rotating speeds locate in the range between 700 and $1100 \mathrm{rpm}$ under an advancing velocity of $110 \mathrm{~mm} / \mathrm{min}$. The peak values of the tensile strength, yield strength and elongation are $426.3 \mathrm{MPa}, \quad 290.1 \mathrm{MPa}$ and $7.0 \%$, respectively $(\omega=700 \mathrm{rpm}$ and $v=110 \mathrm{~mm} / \mathrm{min})$, which can reach 91.5, 94.3 and $35.8 \%$ of the base material counterpart. Rotating speeds outside this range lead to decrease in tensile properties of the repaired specimen, especially for tensile strength and elongation. Similarly, when a constant rotating speed $1100 \mathrm{rpm}$ is adopted, it also exits a suitable range for advancing velocity, i.e., $70-110 \mathrm{~mm} / \mathrm{min}$. The best parameter collaboration is $\omega=1100 \mathrm{rpm}$ and $v=110 \mathrm{~mm} / \mathrm{min}$. Under this situation, the tensile strength, yield strength and elongation of repaired specimen are 422.3 MPa, 275.6 MPa and 6.1\%, respectively (Fig. 11).

Combined with the results in Table 3, Figs. 10 and 11, it demonstrates that the strength of repaired specimens can reach over $90 \%$ that of the base material, but its ductility cannot be effectively restored. It can be seen from Fig. 7 that the repaired specimen contains RZ, TMAZ, HAZ and BM. Moreover, sizes of the grains and precipitates are quite different in different zones. Then, stress and strain concentration could easily take place in the adjacent regions during the loading process, which leads to an inhomogeneous deformation and in turn results in a reduction of ductility.

To a large extent, the main reason for the effect of repairing parameters on tensile properties should be attributed to the heat input caused by the friction between the tool shoulder and the specimen surface [28]. Figure 12 shows typical macro-fractures of two type repaired

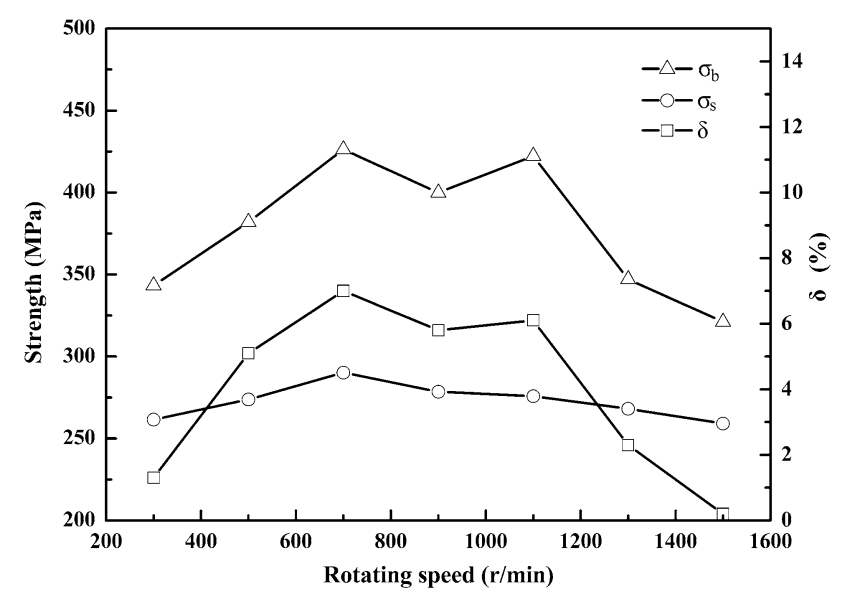

Fig. 10 Effect of rotating speed on the tensile properties of repaired specimens $(v=110 \mathrm{~mm} / \mathrm{min})$

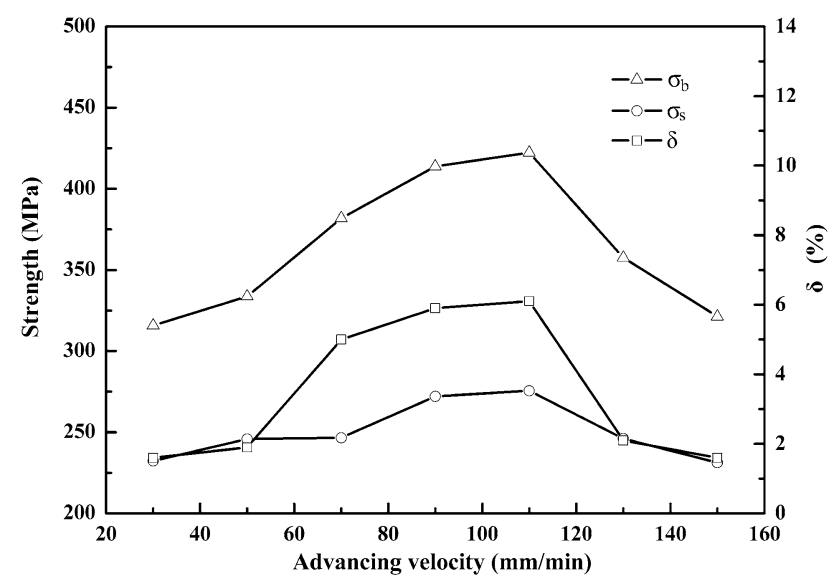

Fig. 11 Effect of advancing velocity on the tensile properties of repaired specimens $(\omega=1100 \mathrm{rpm})$

specimens. By using inappropriate repairing parameters, the heat input and flowability of plastic materials are not sufficient to form good connection between the base material and plastic deformation layer. As a result, the delamination will be introduced in the repaired zone (Fig. 12a). If the optimized repairing parameters were adopted, high-quality repaired zone with few defects can be obtained, as shown in Fig. 12b. Observation of the microfractures reveals that the repaired specimens have typical 

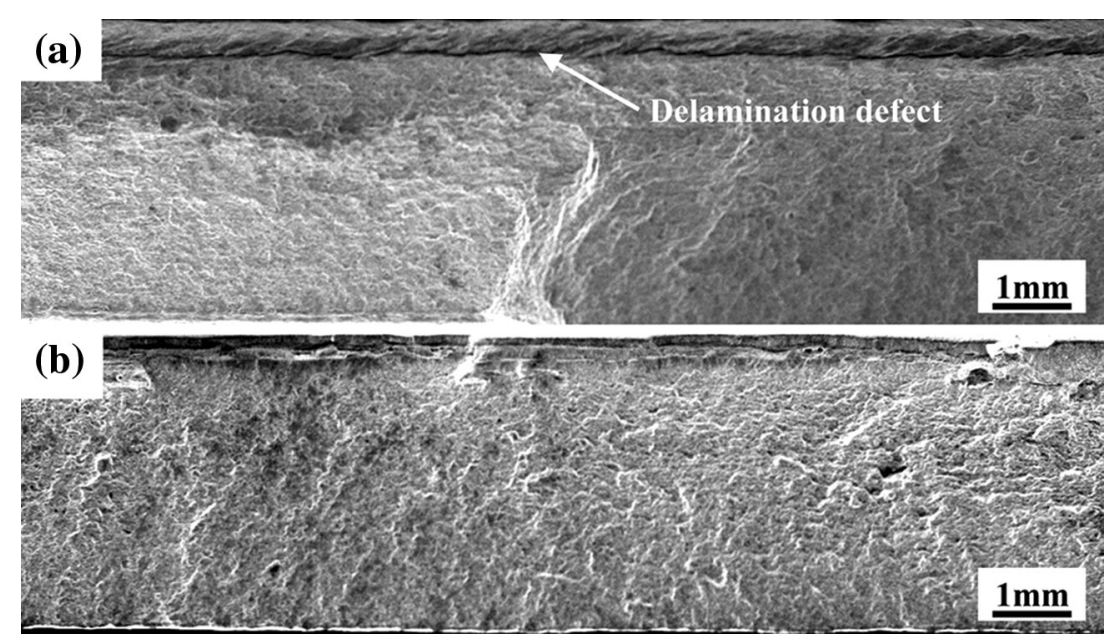

Fig. 12 Macro-fractures of the repaired specimens: a with delamination defect, $\mathbf{b}$ with few defects
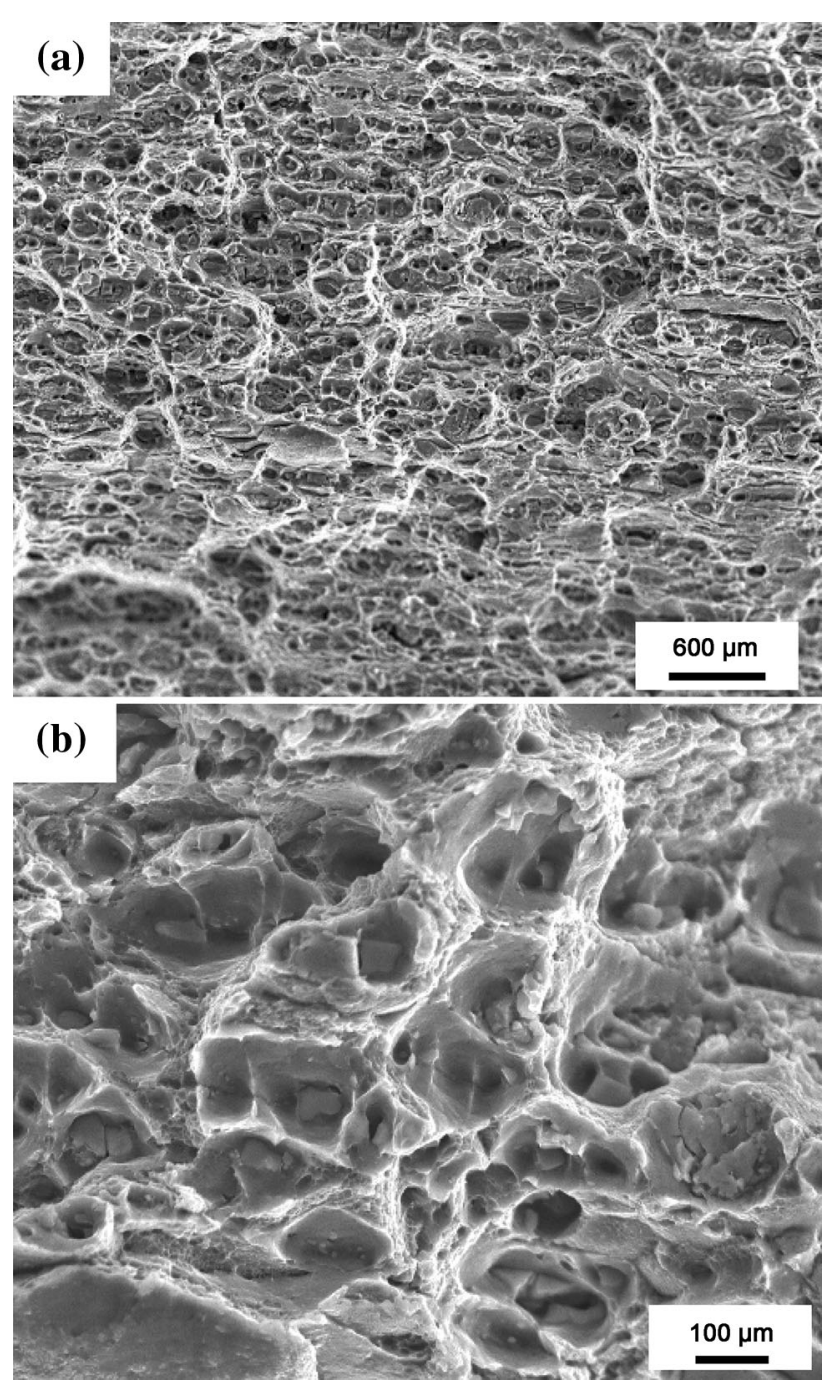

Fig. 13 Micro-fractures of the repaired specimens ductile fracture characteristics with a large number of dimples, as shown in Fig. 13.

\section{Conclusions}

Simulations and experimental studies of friction stir processing repairing in 2024 aluminum alloy plates provided the following conclusions.

1. Temperature measurement results showed that the entire crack repairing is a solid-phase process. Flow pattern of plastic material was regularly along the advancing direction in advancing side, while it is quite chaotic in retreating side.

2. Macrograph of 2024-T4 FS repaired specimen can be divided into four distinguishing zones that exhibit gradually changed characteristics. Larger grain structure and precipitates were refined in RZ; most grains in the TMAZ were elongated; grains and precipitates in HAZ grew to a larger dimension compared to those of the BM. The hardness profiles of the repaired specimen showed typical "W" shape-like, indicating a drop in hardness of the repaired zone.

3. The strength and ductility of FS repaired specimen can been restored. Heat treatment after repairing can further enhance the tensile properties of repaired specimen. Micro-fracture observations revealed that the repaired specimens had typical ductile fracture characteristics.

Acknowledgments This research was jointly supported by the National Natural Science Foundation of China (Grant No. 51405309) and the Natural Science Foundation of Liaoning Province (Grant No. 2015020183). 


\section{References}

[1] S.P. Zhu, Q. Lei, H.Z. Huang, Y.J. Yang, W.W. Peng, Int. J. Damage Mech. (2016). doi:10.1177/1056789516651920

[2] M.D. Sangid, Int. J. Fatigue 57, 58 (2013)

[3] J.Y. Wang, H. Soens, W. Verstraete, N.D. Belie, Cement Concer. Res. 56, 139 (2014)

[4] K.W. Nam, E.S. Kim, Mater. Sci. Eng. A 547, 125 (2012)

[5] M.M. Escobar, S. Vago, A. Vázquez, Compos. Part B Eng. 55, 203 (2013)

[6] S.R. White, N.R. Sottos, P.H. Geubelle, J.S. Moore, M.R. Kessler, S.R. Sriram, E.N. Brown, S. Viswanathan, Nature 409, 794 (2001)

[7] X.X. Chen, A.D. Matheus, O. Kanji, M. Ajit, H.B. Shen, R.N. Steven, K. Sheran, F. Wudl, Science 295, 1698 (2002)

[8] R.P. Wool, Soft Matter 4, 400 (2008)

[9] R.N. Lumley, I.J. Polmear, in Proceedings of the First International Conference on Self-Healing Materials, Noordwijk aan Zee, The Netherlands, April 18-20, 2007

[10] N. Shinya, J. Kyono, K. Laha, in Proceedings of the First International Conference on Self-Healing Materials, Noordwijk aan Zee, The Netherlands, April 18-20, 2007

[11] S. Hautakangas, H. Schut, N.H.V. Dijk, P.E.J. Rivera, D. del Castillo, S.V.D. Zwaag, Scr. Mater. 58, 719 (2008)

[12] A. Hosoi, T. Nagahama, Y. Ju, Mater. Sci. Eng. A 533, 38 (2012)

[13] J.W. Murray, A.T. Clare, J. Mater. Process. Technol. 212, 2642 (2012)
[14] X.G. Zheng, Y.N. Shi, K. Lu, Mater. Sci. Eng. A 561, 52 (2013)

[15] L. Giraud, H. Robe, C. Claudin, C. Desrayaud, P. Bocher, E. Feulvarch, J. Mater, Process. Technol. 235, 220 (2016)

[16] M. Narimani, B. Lotfi, Z. Sadeghian, Mater. Sci. Eng. A 673, $436(2016)$

[17] O.O. Tinubu, S. Das, A. Dutt, J.E. Mogonye, V. Ageh, R. Xu, J. Forsdike, R.S. Mishra, T.W. Scharf, Wear 356-357, 94 (2016)

[18] Z.W. Li, Y.M. Yue, S.D. Ji, P. Chai, L. Wang, Mater. Des. 94, 368 (2016)

[19] Z. Zhang, B.L. Xiao, Z.Y. Ma, Mater. Charact. 106, 255 (2015)

[20] Z.H. Zhang, W.Y. Li, Y. Feng, J.L. Li, Y.J. Chao, Acta Mater. 92, 117 (2015)

[21] X.C. Liu, C.S. Wu, J. Mater. Process. Technol. 225, 32 (2015)

[22] K.S. Arora, S. Pandey, M. Schaper, R. Kumar, J. Mater. Sci. Technol. 26, 747 (2010)

[23] H. Aydın, A. Bayram, D. İsmail, Mater. Des. 31, 2568 (2010)

[24] J. Wang, R. Fu, Y. Li, J. Zhang, Mater. Sci. Eng. A 609, 147 (2014)

[25] A. Simar, Y. Bréchet, B.D. Meester, A. Denquin, C. Gallais, Prog. Mater. Sci. 57, 95 (2012)

[26] H. Aydın, A. Bayram, A. Uğuz, K.S. Akay, Mater. Des. 30, 2211 (2009)

[27] Z. Hu, S. Yuan, X. Wang, Y. Huang, Mater. Des. 32, 5055 (2011)

[28] Z. Li, Y. Yue, S. Ji, P. Chai, Z. Zhou, Mater. Des. 90, 238 (2015) 